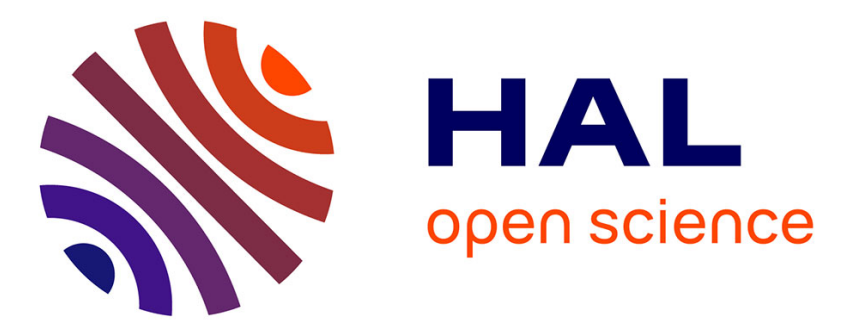

\title{
Tailored Power of an RF Plasma Jet with Admixture of Nitrogen or Oxygen and Its Effects on Human Immune Cells
}

Sander Bekeschus, Sylvain Iséni, Paul Luettjohann, Klaus-Dieter Weltmann

\section{- To cite this version:}

Sander Bekeschus, Sylvain Iséni, Paul Luettjohann, Klaus-Dieter Weltmann. Tailored Power of an RF Plasma Jet with Admixture of Nitrogen or Oxygen and Its Effects on Human Immune Cells. IEEE Transactions on Plasma Science, 2021, 49 (11), pp.3336. 10.1109/TPS.2021.3087199 . hal-03251569

\author{
HAL Id: hal-03251569 \\ https://hal.science/hal-03251569
}

Submitted on 7 Jun 2021

HAL is a multi-disciplinary open access archive for the deposit and dissemination of scientific research documents, whether they are published or not. The documents may come from teaching and research institutions in France or abroad, or from public or private research centers.
L'archive ouverte pluridisciplinaire HAL, est destinée au dépôt et à la diffusion de documents scientifiques de niveau recherche, publiés ou non, émanant des établissements d'enseignement et de recherche français ou étrangers, des laboratoires publics ou privés.

$$
\text { Copyright }
$$




\title{
Tailored Power of an RF Plasma Jet with Admixture of Nitrogen or Oxygen and Its Effects on Human Immune Cells
}

\author{
*Sander Bekeschus, Sylvain Iseni, Paul Lüttjohann and Klaus-Dieter Weltmann
}

\begin{abstract}
Parameter studies of plasma treatment are informative about the optimal use of this technology in biomedical applications such as the argon radio-frequency plasma jet kINPen. However, the interdependence of the plasma-dissipated power in relation to input current and feed gas modulation on the resulting biological consequences has not been studied so far. To this end, a parameter study is presented, and the effect on human immune cell viability was investigated across different input current power and argon with oxygen/nitrogen feed gas admixture settings. It was found that with both nitrogen and oxygen admixtures, a concentration-dependent change in plasma-dissipated power emerged, which converged at $27.5 \mathrm{~mA}$ and $26.5 \mathrm{~mA}$, respectively. The extent of cytotoxicity in immune cells confirmed the relevance of these findings, which were in congruency with the plasmadissipated powers identified. These findings underline the critical role and input parameter-dependent action of plasma sources for biomedical application.
\end{abstract}

Index Terms-CAP, cold atmospheric pressure plasma, cold physical plasma, dissipated power, excitation frequency, gas plasma, monocytes, PBMC, T cells, viability.

\section{INTRODUCTION}

This work focuses on using a radio-frequency (RF) cold atmospheric pressure plasma jet derived from the commercial device kINPen. The main feature and subsequent versions have recently been summarized in a review article [1]. The head of the plasma source used in this study is identical to the kINPen. It consists of a concentric assembly using an alumina capillary of $1.6 \mathrm{~mm}$ diameter with a needle electrode centered on the capillary axis and a grounded ring electrode placed on the outer surface. The capillary is fed with argon (Ar) gas (99.999\% purity, Air Liquide) at a fixed flow rate of 3.0 standard liter per minute (SLM) set with a mass-flow controller (MKS Instruments). The Ar feed gas flows in the capillary towards the tube outlet, expanding into the free space to yield an Ar plume mixing with the ambient air [2,3]. The plasma device was also operated with molecular nitrogen as feed gas only to treat immune cells in this work.

Molecular species from the air - typically $\mathrm{N}_{2}$ and $\mathrm{O}_{2}-$ diffuse into the Ar plume where the ionization waves propagate

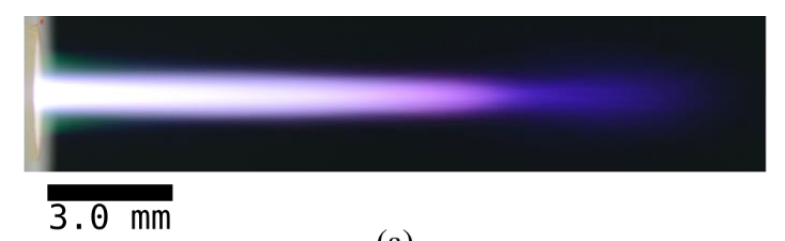

(a)

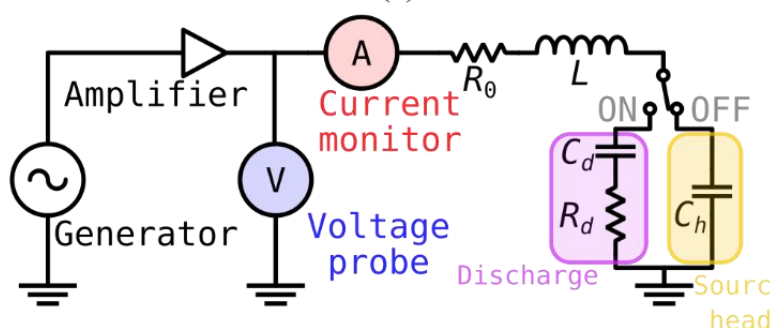

(b)

Fig. 1. Plasma source setup. (a) Photograph of the cold RF atmospheric pressure plasma plume exiting the capillary and expanding in to the ambient air. (Operating conditions: Ar flow rate $3.0 \mathrm{SLM} ; I_{R M S}=44 \mathrm{~mA}$. Camera settings: DSLR Nikon D5100; exposition 0.25 S; ISO 100; focal length $60 \mathrm{~mm}$.). (b) Simplified electrical equivalent circuit of the plasma source with a switch set on plasma off. $R_{0}$ is the impedance accounting for real part of the total device impedance. The inductance $L$ corresponds to the coil in series with the source head when the plasma is OFF, or with the discharge in case of plasma ON.

$[2,4]$, yielding a rich non-equilibrium chemistry of reactive oxygen and nitrogen species (RONS) [5]. To vary the RONS production, admixtures of Ar feed gas with $\mathrm{N}_{2}$ and $\mathrm{O}_{2}$ as precursors can be used. The mole fraction of the molecular admixture ranges from 0 to $1 \%$ in the present work. According to previous studies using this plasma source, the main RONS produced in the discharge and its effluent are nitric oxide (NO) [6], nitric dioxide $\left(\mathrm{NO}_{2}\right)$ [7], hydroxide radical $(\mathrm{OH})$ [8], hydrogen peroxide $\left(\mathrm{H}_{2} \mathrm{O}_{2}\right)$ [9], atomic oxygen $(\mathrm{O})$ [10], singlet oxygen $\left(\mathrm{O}_{2} \mathrm{a}^{1} \Delta_{\mathrm{g}}\right)$ [11], and ozone $\left(\mathrm{O}_{3}\right)$ [12]. An example of the ionization waves propagating in the Ar plume in ambient air is shown in Fig 1a, creating a so-called plasma plume [13]. The interaction of the plasma plume and the liquid surface is key information to consider for several reasons which are beyond the interdisciplinary framework. Direct contact of the plasma with the medium surface will have a significant influence on the discharge, making the liquid part of the electrical circuit and thus affecting the plasma dynamic and chemistry [14]. More specifically, a direct contact of the plasma plume with the liquid

This work was supported by the German Federal Ministry of Education and Research (BMBF), grant numbers 03Z2DN11, 03Z2DN12, and 03Z22DN11. Sander Bekeschus and Sylvain Iséni equally contributed to this work as first authors. Sander Bekeschus (email: sander.bekeschus@inp-greifswald.de) and Klaus-Dieter Weltmann (email: weltmann@inp-greifswald.de) are with the ZIK plasmatis at the Leibniz Institute for Plasma Science and Technology (INP), Felix-HausdorffStr. 2, 17489 Greifswald, Germany. Sylvain Iséni is with the GREMI (Groupe de Recherches sur l'Énergétique des Milieux Ionisés)-UMR7344 CNRS/Université d'Orléans, 14 rue d'Issoudun, BP6744, 45067 Orléans, France (e-mail: sylvain.iseni@univ-orleans.fr). Paul Lüttjohann is with the neoplas GmbH, WalterRathenau-Str. 49A, Greifswald 17489, Germany (e-mail: paul.luettjohann@neoplas.eu). *address correspondence to: sander.bekeschus@inp-greifswald.de 
This article may be downloaded for personal use only. Any other use requires prior permission of the author and IEEE.

This article may be found at doi:10.1109/TPS.2021.3087199.

AIP Publishing is not responsible for any errors or omissions in this version of the manuscript or any version derived from it.

will exert a force on the liquid surface, causing a circulation of the fluid, which is known to transport the long-lived RONS. A prior study of liquid recirculation induced by the plasma and involving the kINPen reports on significant mixing of the treated medium [15].

The kINPen is a plasma jet frequently used in biology and medicine [16]. The device is well known for its wound-healing promoting properties, which was recently underlined in a randomized clinical trial in diabetic patients [17]. Recent advances in the field of plasma medicine have led to suggest some general bases to compare the biological responses induced by different types of plasma sources. Several ways are being discussed, referring to early standardization specifications (DIN 91315) [18] and a generalized concept of plasma-dose $[19,20]$. The latter is based on the dominant role of the reactive oxygen and nitrogen species (RONS) in the plasma affecting cells and tissues, introducing the original concept of equivalent total oxidation potential (ETOP) as a more universal approach to comparing plasma sources' biological effects. Interestingly, the authors of [19] selected a few plasma sources to develop their model, among which the kINPen was part of. The current work aims to control the dissipated power in the plasma accurately in correlation with the cytotoxic responses in human immune cells. This motivation fits in the framework defining standard conditions and highly supports the concept of plasma-dose.

Immune cells respond to plasma treatment in multiple ways [21]. It has been reported that their inflammatory profiles in terms of secretion of chemokines and cytokines are changed following plasma exposure [22, 23]. The ability to take up bacteria has not been found to differ in plasma-treated phagocytes [24]. Moreover, plasma exposure drives the differentiation in myeloid immune cells $[25,26]$. Some immune cell types are more susceptible to plasma-induced cytotoxicity than others [27, 28], which is a consequence of RONS-induced redox regulation that, however, does not affect critical immune

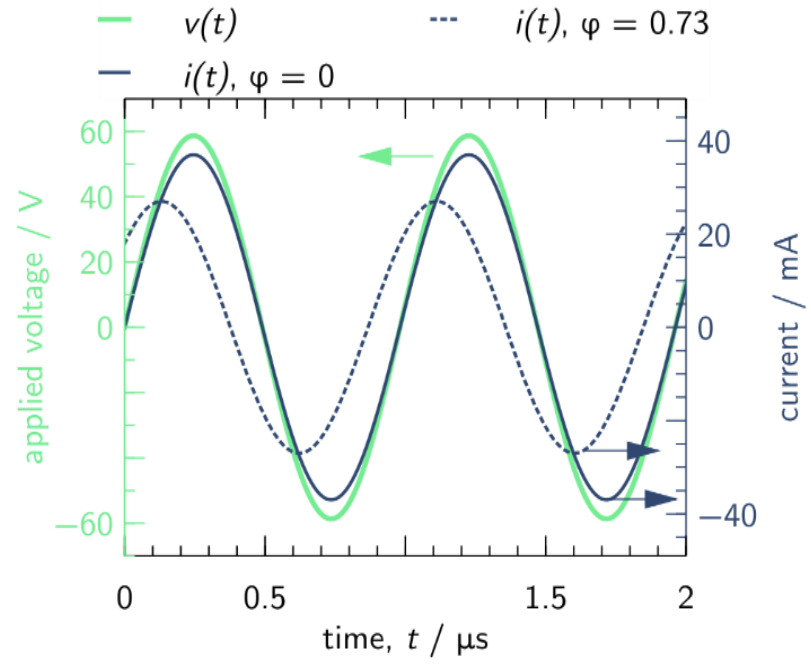

Fig. 2. Applied voltage and current waveforms delivered by the power supply to the circuit. The curves plotted with continuous lines show the current and the voltage in phase $(\varphi=0)$. The dash line corresponds to conditions where current and voltage are shifted by $\varphi=0.73 \mathrm{rad}$. cell function [29, 30]. While the pure argon mode dominates in preclinical studies and the clinical setting, understanding the role of electric and gas input parameters for understanding and optimizing its biomedical effects continues to be of interest from the physics and biology point of view.

\section{EXPERIMENTAL SETUP}

\section{A. Plasma source-kINPen}

The inner needle electrode is electrically excited with an RF power supply to generate a discharge in the kINPen. Unlike most of the studies carried out with the kINPen device, a remote power source was connected to the kINPen head in the present setup. A function generator (AFG3252, Tektronix) was used to produce an RF sinusoidal waveform at a frequency of $1 \mathrm{MHz}$. The sine wave was amplified through a broadband amplifier (SCCX 100, Instruments for Industry) to supply the needle electrode and generate a discharge. As a method of choice, this approach allows for a fine-tuning of the excitation frequency and the signal's amplitude.

The applied voltage waveform, together with the time evolution of the current, are shown in Fig. 2 for two different phase conditions. When the applied voltage and current are in phase, $\varphi=0$ and the maximum power is transferred to the plasma. The coupling is said resistive since no power is reflected back to the generator.

To increase the electric potential at the needle electrode initiating the breakdown, a coil was placed in series with the amplifier and the electrode (Fig. 1b). The inductance ( $L=8.4 \pm 0.4 \mathrm{mH})$, together with the head $\left(C_{h} \approx 3 \mathrm{pF}\right.$ measured with an HM8118 LCR Bridge/Meter, Rohde \& Schwarz) coaxial geometry, can be approximated as a harmonic oscillator characterized by its resonant frequency. In our operating conditions, the resonant frequency was found to be at $f=1.0 \pm 0.3 \mathrm{MHz}$. Unlike typical capacitively-coupled plasmas, no matching box was used that usually is in place to match the complex impedance of the load with the power supply. Instead, a fine-tuning of the RF generator was performed to be at the resonant frequency. Indeed, a conventional matching-box would induce too much energy loss with regard to the total power dissipated in this plasma source, which typically

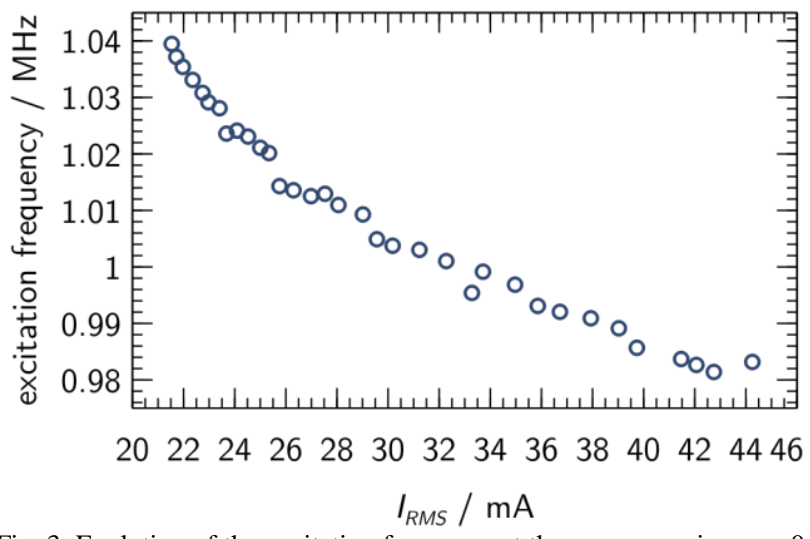

Fig. 3. Evolution of the excitation frequency at the resonance, i.e., $\varphi=0$, depending on the RMS input current. Presently, the current and the voltage have no phase shift. 
This article may be downloaded for personal use only. Any other use requires prior permission of the author and IEEE.

This article may be found at doi:10.1109/TPS.2021.3087199.

AIP Publishing is not responsible for any errors or omissions in this version of the manuscript or any version derived from it.

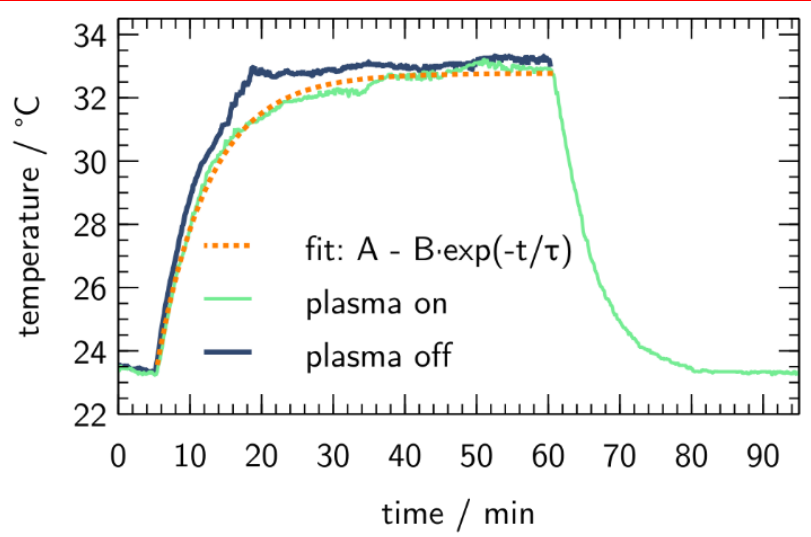

Fig. 4. Time evolution of the temperature of the coil with the plasma ON and with the plasma OFF. The time constant $\tau=7 \mathrm{~min} 20 \mathrm{~s}$. The current was set at $I_{R M S}=35 \mathrm{~mA}$.

dissipates a couple of Watts. This approach was already reported in previous studies involving coaxial RF plasma jets $[14,31]$ and for the $\mu$ APPJ [32]. A voltage probe (P6139A, $C_{\text {probe }}=8.0 \mathrm{pF}, 500 \mathrm{MHz}$, Tektronix) and an $\mathrm{AC}$ current monitor (CT1, $25 \mathrm{kHz}-1 \mathrm{GHz}$ bandwidth, Tektronix) were used to measure the applied voltage and total current before the coil. The position of the voltage probe is discussed in the next section. Both probes were connected to an oscilloscope (DPO 4104, Tektronix) to record the measured signals. The temperature of the coil was measured with a miniaturized fiber optic thermometer (FOTEMP1-OEM, Optocon).

\section{MATERIALS AND MethODS}

\section{A. Electrical power measurement}

The determination of the power input coupled to the plasma is crucial to understand better the discharge regime and the elementary processes governing the reactive non-equilibrium chemistry. While several electrical parameters can be measured in dielectric barrier discharges (DBD) with the known $Q-V$ plot techniques [33], the latter implementation is limited with excitation frequencies above $500 \mathrm{kHz}$. As a general statement, instantaneous electrical power can be defined as the product of the voltage with the current. In the case of an AC excitation waveform with a period $T$ (with $T=1 / f$ ), the average power during a single period reads,

$$
P=\frac{1}{T} \int_{t}^{t+T} u(t) \cdot i(t) d t
$$

with $u(t)$ and $i(t)$ being the immediate voltage and current values, respectively. Using a sinusoidal excitation waveform offered the possibility to refer to root-mean-square values of $u(t)$ and $i(t)$ such as, $U_{R M S}=U_{\text {peak }} / \sqrt{2}$ and $I_{R M S}=I_{\text {peak }} / \sqrt{2}$. Thus, the average power is now defined as,

$$
P=U_{R M S} \cdot I_{R M S} \cdot \cos (\varphi),
$$

with $\varphi$ being the phase shift between the applied voltage and the current. $\varphi$ is directly linked to the complex impedance of the circuit load, i.e., the presence or absence of the discharge and the discharge regime.

While in previous studies using the kINPen, the excitation frequency was fixed [34-36], and some authors chose to characterize the phase shift $\varphi$ to infer the power values [31,37],

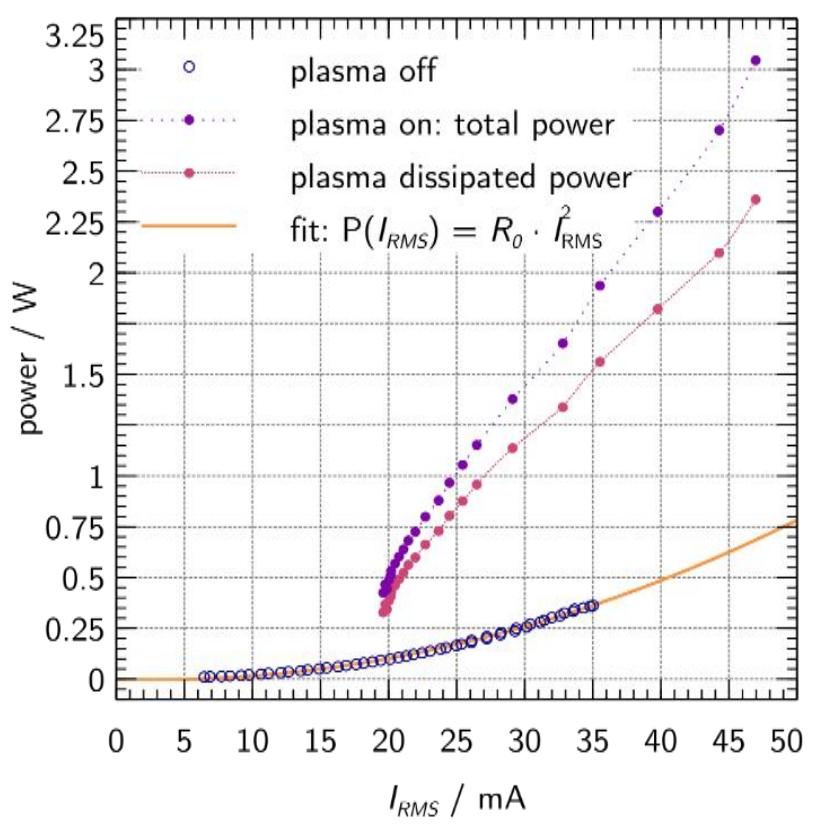

Fig. 5. Electrical power of the plasma jet device as a function the RMS current $\left(I_{R M S}\right)$ with plasma OFF and plasma ON. The quadratic fit curve describes the Joule heating of the whole circuit with $\mathrm{R}=352 \pm 5 \Omega$. The plasma-dissipated power equals the difference between the power with plasma ON and the plasma OFF.

this current work suggests another approach. As mentioned previously, the excitation frequency is fine-tuned to the resonant frequency of the circuit, meaning that $\varphi=0$. This condition allows for an efficient coupling for the power supply with the plasma source where the impedance is purely resistive.

Fig. 3 shows the evolution of the excitation frequency for $\varphi=0$. To satisfy this condition, the excitation frequency was fine-tuned on the signal generator until the current and voltage are in phase. Thus, the resulting frequency is the resonant frequency, maximizing the energy transfer from the electrical circuit to the plasma. By increasing the applied voltage, the resonant frequency slightly drifts but does not exceed $6 \%$ of the full range. It is safely assumed that this variation of resonant frequency will have a negligible impact on the discharge mechanisms. This assumption is also valid for the electron properties (temperature and density), which are not affected by these excitation frequency changes. Practically, the value of $\varphi$ was permanently measured with the oscilloscope and set to zero by adjusting the generator frequency accordingly.

\section{B. Power losses without discharge}

Power loss is a major concern while using RF plasmas and often refers to a mismatch between the generator and the load, i.e., the plasma reactor. Apart from the plasma source head and its coaxial geometry with the behavior of a capacitor, the coil is a component where energy losses should be investigated. An important effect responsible for the electrical losses in conductors is the Joule heating.

Fig. 4 presents the temperature of the coil with and without plasma for a fixed current value. Both curves exhibit an apparent increase of temperature of about $10^{\circ} \mathrm{C}$ to stabilize at $32{ }^{\circ} \mathrm{C}$. Comparing the temperature evolution with and without 
This article may be downloaded for personal use only. Any other use requires prior permission of the author and IEEE.

This article may be found at doi:10.1109/TPS.2021.3087199.

AIP Publishing is not responsible for any errors or omissions in this version of the manuscript or any version derived from it.

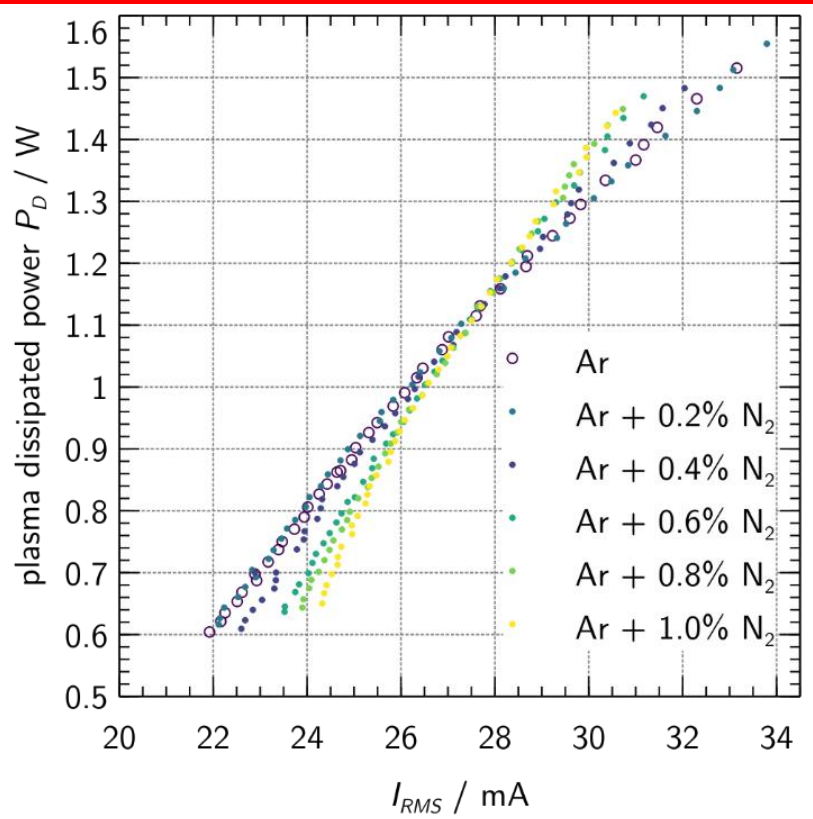

Fig. 6. Plasma-dissipated power $\left(P_{D}\right.$, $)$ evolution versus the $I_{R M S}$ for several gas mixture of $\mathrm{Ar}$ with $\mathrm{N}_{2}$ ranging from $0 \%$ to $1 \%$.

plasma shows a somewhat similar behavior also in absolute value. The minor discrepancies around 20 min do not exceed $2{ }^{\circ} \mathrm{C}$ and thus are negligible, particularly regarding the coil's thermal response. Joule heating is responsible for this temperature rise. Quantitatively, one concludes that the energy loss by Joule heating is independent of the discharge ignition. This was also the case of the $\mu$ APPJ [32]. An excellent match with a fit of an exponential function finds the time constant $\tau=7 \mathrm{~min} 20 \mathrm{~s}$. Therefore, the plasma jet was systematically switched on for at least 35 min to reach a steady-state regime before the treatment of the human cell samples started.

\section{C. $\quad$ Plasma-dissipated power $\left(P_{D}\right)$}

The approach used in this work was more straightforward to implement than the $Q-V$ plot, but it required clarifying the voltage probe's role in the electrical circuit. As shown in Fig. 1(b), the voltage probe is not connected directly to the powered electrode but before the coil. This is explained by the probe capacitance, which is of the same order as the coaxial plasma head $\left(C_{\text {probe }} \approx C_{h}\right)$. If the voltage probe were placed in parallel with the electrode, the uncertainties on the measured potential would exceed $50 \%$, which is not acceptable in the present case. This is in agreement with the recommendations found in the literature [31,38].

Fig. 5 presents the averaged dissipated power versus the RMS current supplied to the plasma device with and without discharge. In the case of plasma OFF, the dissipated power is mainly attributed to the Joule heating, as previously discussed. To support this argumentation, a remarkable match is found between the experimental data and a quadratic fit describing the dissipated power converted from electrical energy to heat. This is consistent with the temperature evolution of the coil previously reported. The curve of the total dissipated power with plasma ON exhibits a monotonic linear evolution with the increase of $I_{R M S}$. The plasma-dissipated power $\left(P_{D}\right)$ now cancels

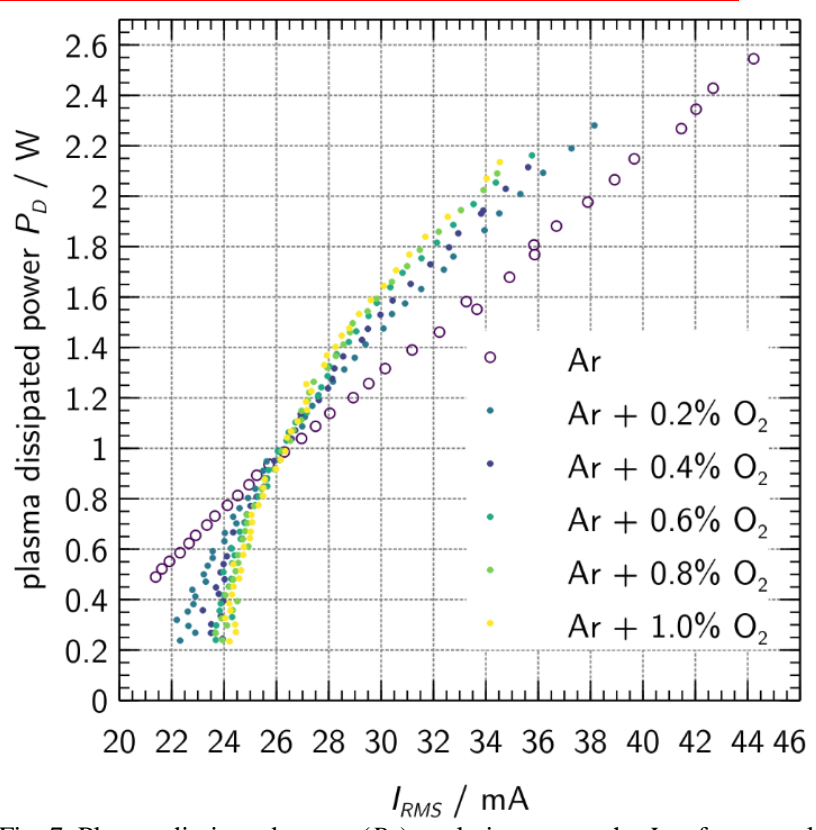

Fig. 7. Plasma-dissipated power $\left(P_{D}\right)$ evolution versus the $I_{R M S}$ for several gas mixture of $\mathrm{Ar}$ with $\mathrm{O}_{2}$ ranging from $0 \%$ to $1 \%$.

out the quadratic shape. The latter can be determined such as $P_{D}=P_{O N}-P_{O F F}$. Practically, the advantage of the quadratic fit function is twofold: it allows for predicting employing an extrapolation of the power loss by Joule heating at current values higher than $I_{R M S}=35 \mathrm{~mA}$. Under the present conditions, it is not possible to prevent the breakdown at higher current values. Secondly, the analytical function is conveniently used to subtract the power without plasma from the total power at the exact same value of $I_{R M S}$. It contributes to enhancing the accuracy of the method. With this regard, the relative uncertainties have been estimated to do not exceed $6 \%$ for all the power values reported in this study.

\section{Biological experiments}

Human peripheral blood mononuclear cells (PBMCs) were isolated as previously described [29]. This cellular fraction contains monocytes and $\mathrm{T}$ helper cells, among others, that can be stained with fluorescently labeled monoclonal antibodies targeting cluster of differentiation (CD)4 (T helper cells) and CD14 (monocytes) for their analysis. For plasma experiments, $5 \times 10^{5}$ cells were seeded in 500 $\mu$ of Roswell Park Memorial Institute (RPMI) 1640 cell culture medium containing 10\% fetal bovine serum, $2 \%$ penicillin/streptomycin, and $1 \%$ glutamine. Plasma treatment was performed as indicated, at a treatment distance of $10 \mathrm{~mm}$ (non-contact), followed by a $24 \mathrm{~h}$ incubation period at $37^{\circ} \mathrm{C}, 95 \%$ relative humidity, and $5 \% \mathrm{CO}_{2}$. Subsequently, cells were collected in FACS tubes, washed twice with phosphate-buffered saline (PBS), and stained with allophycocyanine-conjugated anti-CD4 and phycoerythrinconjugated anti-CD14 monoclonal antibodies (BioLegend) in Annexin V binding buffer containing Annexin V fluoresceinthiocyanate and 4',6-diamidino-2-phenylindole (DAPI, $1 \mu \mathrm{M}$ ) for analysis of cell viability by multicolor flow cytometry using a Gallios (Beckman-Coulter). Data analysis was performed using Kaluza software version 2.1.1 (Beckman-Coulter). To 
This article may be downloaded for personal use only. Any other use requires prior permission of the author and IEEE.

This article may be found at doi:10.1109/TPS.2021.3087199.

AIP Publishing is not responsible for any errors or omissions in this version of the manuscript or any version derived from it.

analyze ROS production, fully supplemented cell culture medium was plasma-treated, and amplex ultra red (ThermoFisher) was added before assaying the resulting fluorescence in a multimode plate reader (Tecan) at $\lambda_{\text {ex }} 535 \mathrm{~nm}$ and $\lambda_{\mathrm{em}} 590 \mathrm{~nm}$. Data display and statistical analysis were done using prism 9.02 (GraphPad software).

\section{RESULTS AND DISCUSSION}

\section{A. Plasma-dissipated power in Ar- $\mathrm{N}_{2}$ admixture}

The RONS produced by the same type of plasma jet have been extensively investigated $[1,11,39]$. The dissipated power is a crucial parameter to tune the net production of the RONS in the plasma core and the plasma plume. In this study, fractions of molecular nitrogen were added to the Ar buffer gas, similar to the authors' prior works [3].

Fig. 6 shows the plasma-dissipated power in case of admixture of $\mathrm{N}_{2}$ up to $1.0 \%$. Although the general trend describes a monotonic increase of $P_{D}$ while increasing the input current, one notices several vital features. The operating current range is more extensive in pure Ar than in an admixture containing $\mathrm{N}_{2}$. With $1.0 \% \mathrm{~N}_{2}$, the ignition occurs with a current being $2 \mathrm{~mA}$ higher than in pure Ar while $P_{D}$ remains relatively similar around $0.65 \mathrm{~W}$. This is explained by the additional processes to excite and ionize $\mathrm{N}_{2}$ molecules, which create additional losses compared to the pure Ar case needing less energy for excitation and ionization. According to Gaens et al. [40], $\mathrm{N}_{2}$ molecules in the buffered gas will be in favor of producing $\mathrm{N}_{2}(\mathrm{~A})$ metastable states [41], which is the main pathway to contribute to the nitric oxide (NO) chemistry [6]. $\mathrm{NO}$ being the precursor of nitric dioxide $\left(\mathrm{NO}_{2}\right)$, which has a longer lifetime and reacts with long-living compounds such as ozone $\left(\mathrm{O}_{3}\right)$.

Intriguingly, all the curves of $P_{D}$ measured for different fractions of $\mathrm{N}_{2}$ converge in a single point at $I_{R M S}=27.5 \mathrm{~mA}$ for which corresponds to $P_{D}=1.1 \mathrm{~W}$. This means that setting the input current at this specific value will always result in the same dissipated power for all molar fraction of $\mathrm{N}_{2}$ ranging from $0 \%$ to $1 \%$. Although this feature is not well understood, it is of significant interest while applying this plasma source in the context of plasma exposure of human cells. Indeed, it is expected that the net production of RONS is directly related to the plasma-dissipated power and the mole fraction added to the Ar gas [40, 42].

\section{B. Plasma-dissipated power in $\mathrm{Ar}-\mathrm{O}_{2}$ admixture}

The production of RONS in plasma jets involves the contribution of molecular oxygen as a precursor. With $\mathrm{O}_{2}$ admixture, the main reactive species known to be produced in this plasma source are atomic oxygen $(\mathrm{O})$, singlet oxygen $\left(\mathrm{O}_{2}(\mathrm{a} A)\right)$, and $\mathrm{O}_{3}[40]$, which are known to be biologically active [42]. Investigating the plasma-dissipated power in the case of $\mathrm{Ar}-\mathrm{O}_{2}$ admixture is interesting towards the output reactive chemistry, and the understanding of elementary processes since atomic and molecular oxygen are electro-negative compounds. An influence on the electron properties is expected, such as the electrostatic focusing mechanism responsible for the

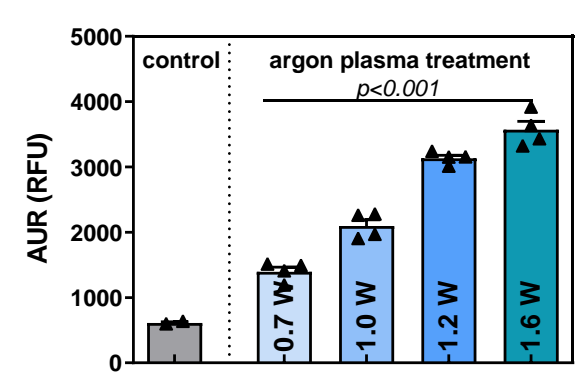

Fig. 8. Plasma-generated ROS in treated cell culture medium increase with increasing $I_{R M S}$ resulting in the dissipated powers as shown. AUR: amplex ultra red; RFU: relative fluorescent units; statistics: one-way analysis of variances for linearity.

confinement of the electric field along the jet axis [43].

Fig. 7 presents the plasma-dissipated power for several fractions of $\mathrm{O}_{2}$ added to the Ar gas ranging from $0 \%$ to $1.0 \%$. While in the case of Ar- $\mathrm{N}_{2}$ admixtures, the general trend was similar to the pure Ar condition, low mole fractions of $\mathrm{O}_{2}$ reveal a significant effect on $P_{D}$. The current range to operate the plasma jet is reduced with an increase of $\mathrm{O}_{2}$ fractions. This is explained by the additional electron losses due to the attachment to form negative oxygen ions. Surprisingly, the same unique feature is observed with the convergence of all the curves measured for a different fraction of $\mathrm{O}_{2}$. Indeed, a current of $I_{R M S}=26.5 \mathrm{~mA}$ corresponds to $P_{D}=1.0 \mathrm{~W}$, which is unique for all $\mathrm{O}_{2}$ admixture up to $1.0 \%$. The reason for this observation has not been understood yet. The slight difference between both gases suggests that the underlying mechanisms are related to the fundamental of gas discharges. However, due to the drastic difference nature of an $\mathrm{N}_{2}$ seeded and $\mathrm{O}_{2}$ seeded discharge, the authors hypothesize that this feature may also result from a geometric characteristic of the plasma source. A detailed understanding of this specific feature would require an extended plasma chemical kinetics model accounting for the main chemical species. To the best of our knowledge, such a feature has not been found in the literature for other plasma jets yet, which supports the hypothesis of the findings being a specificity of the current plasma source design.

\section{Biological effects of plasma-dissipated power and feed gas modulation on immune cells}

To analyze the biomedical effects of the findings, the ROS generated of different input currents and the resulting plasmadissipated powers were measured in cell culture medium. A significant linear relation of increasing input current and ROS output was found in the plasma-treated cell culture medium (Fig. 8). Next, the effect of varying the input current affecting the plasma-dissipated powers was investigated by analyzing the viability of human immune cells. This can be done conveniently using multicolor flow cytometry. By analyzing the fluorescence intensity of Annexin V as apoptosis marker, and DAPI as late apoptosis/necrosis marker, the percentage of viable (Annexin $\mathrm{V}^{-} / \mathrm{DAPI}^{-}$) cells can be assessed as shown representatively for density distributions and overlay histograms of PBMCs for different plasma treatment times with at least 20,000 cells per sample (Fig. 9a). The larger population in the lower-left corner of the plots represents cells that did not stain for both Annexin 
This article may be downloaded for personal use only. Any other use requires prior permission of the author and IEEE.

This article may be found at doi:10.1109/TPS.2021.3087199.

AIP Publishing is not responsible for any errors or omissions in this version of the manuscript or any version derived from it.
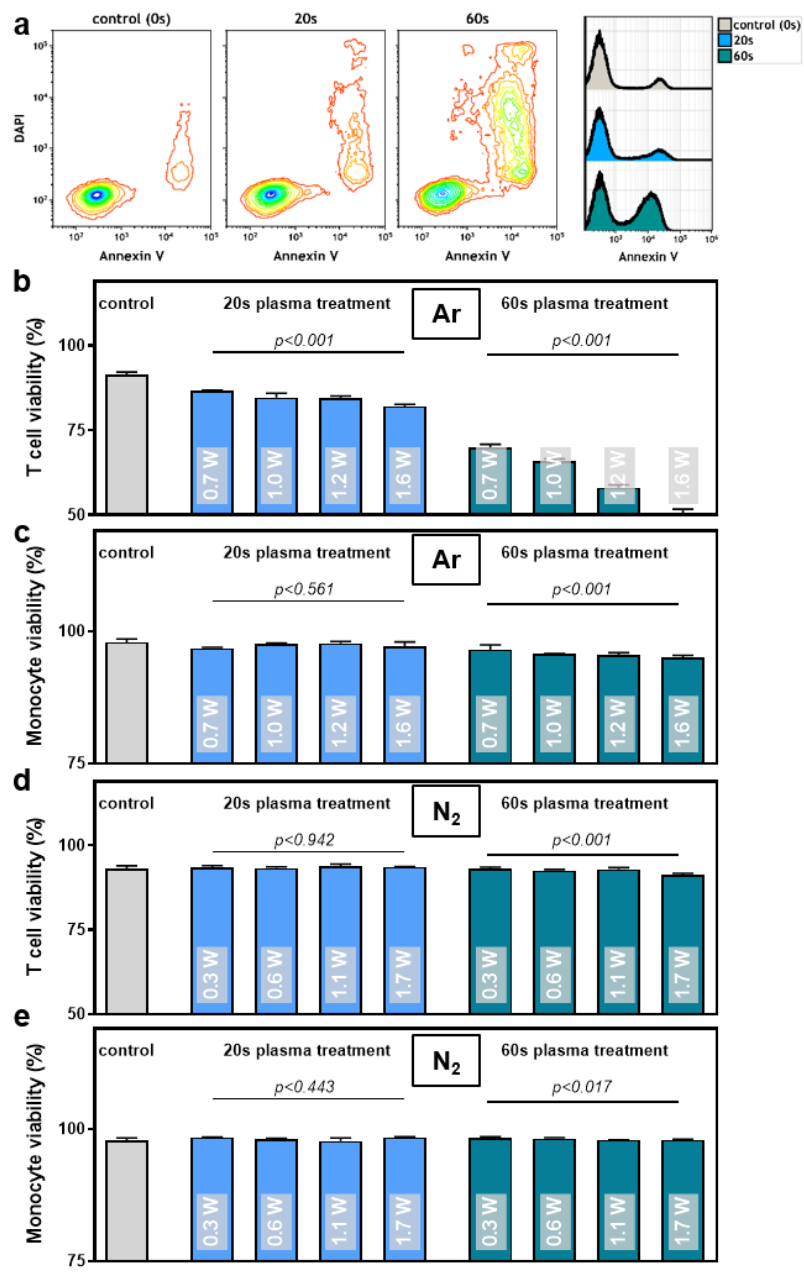

Fig. 9. (a) Counter plots (left) of untreated and plasma-treated PBMC 24h after exposure that were stained with Annexin V and DAPI that demarcate dying or dead cells, respectively, while the live cell population is negative for both Annexin V and DAPI; the Annexin V histogram (right) visualizes the increase of dying cells; (b-e) percentages of viable lymphocytes (b) and monocytes (c) when changing input currents and subsequent dissipated power in the pure argon plasma treatment settings, and of lymphocytes (d) and monocytes (e) in plasma treatment with pure $\mathrm{N}_{2}$ as feed gas. Statistical analysis by one-way analysis of variances against $p<0.05$ shows a significant interrelation between input current and toxicity across all settings and cells types investigated for the 60s treatment time.

$\mathrm{V}$ and DAPI, thus demarcating the viable cell population. It can be appreciated that the cell populations being positive for either Annexin V indicating early apoptotic cells or both Annexin V and DAPI indicating late apoptotic cells increases with longer plasma times. This is more clearly visible in the histograms (Fig. 9a, right images) that show an increased proportion of Annexin $\mathrm{V}$ positive (apoptotic) cells with increasing plasma treatment times. This also indicates a treatment time-dependent effect. Quantitative analysis of T cells subsequently showed a viability decrease with increasing input currents (and hence, plasma-dissipated powers) for both plasma treatment times investigated (Fig. 9b). These trends were significant. It is known that monocytes are much less susceptible to plasmainduced cytotoxic effects [44]. The results obtained in the current study are in line with these findings (Fig. 9c). Notwithstanding, a significant trend of increased cytotoxicity

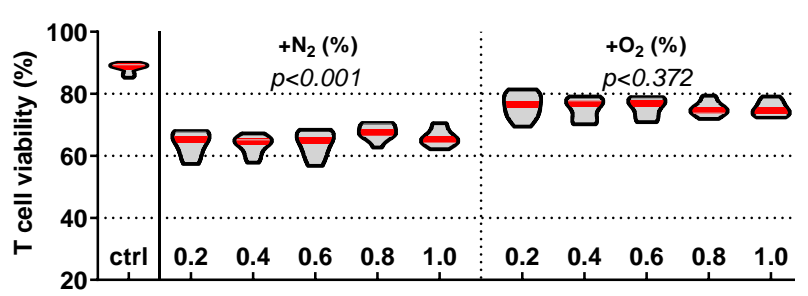

Fig. 10. T cell viability $24 \mathrm{~h}$ after plasma treatment with $\mathrm{N}_{2}$ or $\mathrm{O}_{2}$ admixed argon plasma $(0.2,0.4,0.6,0.8$., and 1.0 percent $)$. Plasma treatment time was $60 \mathrm{~s}$, input current was $26.5 \mathrm{~mA}$. Statistical analysis was done by oneway analysis of variances against $p<0.05(*)$ and test for trend.

of higher input current treatment setups with subsequent changes in dissipated powers was also found in monocytic cells, albeit the absolute effect size was modest. Next, the role of reactive nitrogen species (RNS) on cell viability was investigated for the kINPen operated in pure $\mathrm{N}_{2}$ feed gas. This setting is a peculiarity of this study since the kINPen has not been reported to operate in pure $\mathrm{N}_{2}$ feed gas [1]. To compare with the previous conditions, the dissipated power was set within the same range as for the $\mathrm{Ar} / \mathrm{N}_{2}$ and $\mathrm{Ar} / \mathrm{O}_{2}$ feed gas mixtures. While toxicity was nearly absent in both $\mathrm{T}$ cells (Fig. 9d) and monocytes (Fig. 9e), a significant trend of slightly higher amounts of dead cells with increasing input currents (and subsequent plasma-dissipated powers) was also observed in this case. Next, the goal was to relate the findings of the feed gas alteration in relation to plasma-dissipated power to cytotoxic effects in human immune cells. To this end, the $I_{R M S}$ of $26.5 \mathrm{~mA}$ was used for $\mathrm{Ar} / \mathrm{N}_{2}(0.2 \%$ to $1.0 \%)$ and $\mathrm{Ar} / \mathrm{O}_{2}(0.2 \%$ to $1.0 \%)$ plasma treatment (60s). At this input current, the resulting power differences upon $\mathrm{N}_{2}$ admixtures were modest but measureable (Fig. 6), with admixtures resulting in a lower plasma-dissipated power at the $I_{R M S}$ of $26.5 \mathrm{~mA}$. According to the linearity of power and RONS generation (Fig. 8), the $\mathrm{N}_{2}$ admixture should lead to less RONS production and less cytotoxic effects. Strikingly, this finding was confirmed in immune cells plasma-treated with the conditions mentioned above (Fig. 10, left panel). For $\mathrm{O}_{2}$ admixture at $I_{R M S}$ of $26.5 \mathrm{~mA}$, no differences in plasma-dissipated power were observed (Fig. 7). Hence, similar levels of RONS should be produced, leading to similar cytotoxic activity. Again, this was confirmed in immune cells plasma-treated with the conditions mentioned above (Fig. 10, right panel). Moreover, the $\mathrm{O}_{2}$ admixtures were generally less toxic compared to $\mathrm{N}_{2}$ admixtures. This correlates to previous findings caused by more RNS and more $\mathrm{H}_{2} \mathrm{O}_{2}$ being generated with $\mathrm{N}_{2}$ over $\mathrm{O}_{2}$ admixture, while a simultaneous admixture of both $\mathrm{N}_{2}$ and $\mathrm{O}_{2}$ yields RONS level even lower than those found with $\mathrm{O}_{2}$ admixture alone [45]. The underlying mechanism is unclear but might relate to $\mathrm{O}_{2}$ interfering with ionization processes more heavily than $\mathrm{N}_{2}$ admixed at equivalent amounts. Altogether, these data provide a link between feed gas conditions, plasma-dissipated power, and biological consequences as observed for the kINPen and the $\mu \mathrm{APPJ}$ before [26-28]. This study, therefore, rationalizes the investigation of plasma-dissipated power over input currents in plasma jets to foster an understanding of their biomedical effects further. 
This article may be downloaded for personal use only. Any other use requires prior permission of the author and IEEE.

This article may be found at doi:10.1109/TPS.2021.3087199.

AIP Publishing is not responsible for any errors or omissions in this version of the manuscript or any version derived from it.

\section{CONCLUSION}

The input current and feed gas mixture have dedicated effects on the argon jet's plasma-dissipated power in this study. A common dissipated power is found between the pure Ar feed gas and the $\mathrm{Ar} / \mathrm{N}_{2}$ and $\mathrm{Ar} / \mathrm{O}_{2}$ admixtures up to $1.0 \%$. In this study, the kINPen was operated with pure $\mathrm{N}_{2}$ as a feed gas and applied for the first time to treat human immune cells, and no cytotoxic effect was observed with this gas condition. Conveniently, in $\mathrm{Ar} / \mathrm{N}_{2}$ and $\mathrm{Ar} / \mathrm{O}_{2}$ admixtures, a converging point was found at $25.7 \mathrm{~mA}$ and $26.5 \mathrm{~mA}$, respectively. This unique setting allows to dissipate around $1 \mathrm{~W}$ and is rigorously monitored in situ with non-invasive measurements of $I_{R M S}$. Such monitoring can be easily implemented with conventional electrical probes and does not require extensive techniques. In this manner, the present approach is simple and supports the interdisciplinary studies of plasma applied in a biomedical context. The dose of the treated samples can be accurately controlled by measuring the critical parameter $I_{R M S}$. The current study identified that the relation between $I_{R M S}$ and plasmadissipated power translated accordingly into RONS formation and, eventually, cytotoxic effects in immune cells. This is the first time a relation between feed gas composition, input current variation, plasma power, RONS, and the biological response was identified conjointly in a single study. Nevertheless, additional plasma diagnostics such as OES, more detailed liquid analysis, and different cellular readout systems may help to disentangle the mechanisms at play to a greater extent. Altogether, this study emphasizes the need for crossdisciplinary studies to elucidate the inter-connectivity between electric and feed gas parameters and subsequent biological consequences following exposure to plasma sources.

\section{ACKNOWLEDGMENT}

The technical support of A. Müller and Dr. R. Kensbock is greatly appreciated. S. I. thanks Dr. A. V. Pipa and Prof. Dr. St. Reuter for the fruitful discussion about electrical diagnostics.

\section{REFERENCES}

S. Reuter, T. von Woedtke, and K. D. Weltmann, "The kINPen-a review on physics and chemistry of the atmospheric pressure plasma jet and its applications," J. Phys. D: Appl. Phys., vol. 51, no. 23, Jun 132018. Reuter, "Atmospheric pressure streamer follows the turbulent argon air boundary in a $\mathrm{MHz}$ argon plasma jet investigated by $\mathrm{OH}$-tracer PLIF spectroscopy," J. Phys. D: Appl. Phys., vol. 47, no. 15, p. 152001, Apr 162014.

[3] S. Bekeschus, S. Iseni, S. Reuter, K. Masur, and K. D. Weltmann, "Nitrogen Shielding of an Argon Plasma Jet and Its Effects on Human Immune Cells," IEEE Trans. Plasma Sci., vol. 43, no. 3, pp. 776-781, Mar 2015.

[4] S. Iseni, S. Reuter, A. Schmidt-Bleker, and K. D. Weltmann, "Flow and Discharge Development in an Argon Atmospheric Pressure Plasma Jet Observed by ICCD and PLIF Imaging," IEEE Trans. Plasma Sci., vol. 42, no. 10, pp. 2458-2459, Oct 2014.

[5] A. Schmidt-Bleker, J. Winter, S. Iseni, M. Dunnbier, K. D. Weltmann, and S. Reuter, "Reactive species output of a plasma jet with a shielding gas device-combination of FTIR absorption spectroscopy and gas phase modelling," J. Phys. D: Appl. Phys., vol. 47, no. 14, p. 145201, Apr 92014.

[6] S. Iseni, S. Zhang, A. F. H. van Gessel, S. Hofmann, B. T. J. van Ham, S. Reuter, et al., "Nitric oxide density distributions in the effluent of an RF argon APPJ: effect of gas flow rate and substrate," New J. Phys., vol. 16, no. 12, p. 123011, Dec 22014.

[7] S. Iseni, S. Reuter, and K. D. Weltmann, "NO2 dynamics of an Ar/Air plasma jet investigated by in situ quantum cascade laser spectroscopy at atmospheric pressure," J. Phys. D: Appl. Phys., vol. 47, no. 7, p. 075203, Feb 192014.

[8] T. Verreycken, R. Mensink, R. v. d. Horst, N. Sadeghi, and P. J. Bruggeman, "Absolute $\mathrm{OH}$ density measurements in the effluent of a cold atmospheric-pressure $\mathrm{Ar}-\mathrm{H} 2 \mathrm{O}$ RF plasma jet in air," Plasma Sources Sci. T., vol. 22, no. 5, p. 055014, 2013.

[9] J. Winter, K. Wende, K. Masur, S. Iseni, M. Dunnbier, M. U. Hammer, et al., "Feed gas humidity: a vital parameter affecting a cold atmospheric-pressure plasma jet and plasma-treated human skin cells," J. Phys. D: Appl. Phys., vol. 46, no. 29, p. 295401, Jul 242013.

[10] S. Reuter, J. Winter, A. Schmidt-Bleker, D. Schroeder, H. Lange, N. Knake, et al., "Atomic oxygen in a cold argon plasma jet: TALIF spectroscopy in ambient air with modelling and measurements of ambient species diffusion," Plasma Sources Sci. T., vol. 21, no. 2, p. 024005, Apr 2012.

[11] H. Jablonowski, J. Santos Sousa, K. D. Weltmann, K. Wende, and S. Reuter, "Quantification of the ozone and singlet delta oxygen produced in gas and liquid phases by a non-thermal atmospheric plasma with relevance for medical treatment," Sci. Rep., vol. 8, no. 1, p. 12195, Aug 152018.

[12] S. Reuter, J. Winter, S. Iseni, S. Peters, A. Schmidt-Bleker, M. Dunnbier, et al., "Detection of ozone in a MHz argon plasma bullet jet," Plasma Sources Sci. T., vol. 21, no. 3, p. 034015, Jun 2012.

[13] J. Jarrige, M. Laroussi, and E. Karakas, "Formation and dynamics of plasma bullets in a non-thermal plasma jet: influence of the highvoltage parameters on the plume characteristics," Plasma Sources Sci. T., vol. 19, no. 6, 2010.

[14] S. Hofmann, K. van Gils, S. van der Linden, S. Iseni, and P. Bruggeman, "Time and spatial resolved optical and electrical characteristics of continuous and time modulated RF plasmas in contact with conductive and dielectric substrates," Eur. Phys. J. D, vol. 68, no. 3, pp. 1-14, Mar 212014.

[15] J. F. M. van Rens, J. T. Schoof, F. C. Ummelen, D. C. van Vugt, P. J. Bruggeman, and E. M. van Veldhuizen, "Induced Liquid Phase Flow by RF Ar Cold Atmospheric Pressure Plasma Jet," IEEE Trans. Plasma Sci., vol. 42, no. 10, pp. 2622-2623, 2014.

[16] S. Bekeschus, A. Schmidt, K.-D. Weltmann, and T. von Woedtke, "The plasma jet kINPen - A powerful tool for wound healing," Clin. Plas. Med., vol. 4, no. 1, pp. 19-28, 2016.

[17] B. Stratmann, T. C. Costea, C. Nolte, J. Hiller, J. Schmidt, J. Reindel, et al., "Effect of Cold Atmospheric Plasma Therapy vs Standard Therapy Placebo on Wound Healing in Patients With Diabetic Foot Ulcers: A Randomized Clinical Trial," JAMA Netw Open, vol. 3, no. 7, p. e2010411, Jul 12020.

[18] M. S. Mann, R. Tiede, K. Gavenis, G. Daeschlein, R. Bussiahn, K.D. Weltmann, et al., "Introduction to DIN-specification 91315 based on the characterization of the plasma jet kINPen ${ }^{\circledR}$ MED," Clin. Plas. Med., vol. 4, no. 2, pp. 35-45, 2016.

[19] H. Cheng, J. Xu, X. Li, D. Liu, and X. Lu, "On the dose of plasma medicine: Equivalent total oxidation potential (ETOP)," Physics of Plasmas, vol. 27, no. 6, 2020.

[20] A. A. Fridman, A. Lin, V. Miller, S. Bekeschus, K. Wende, and K.D. Weltmann, "The Plasma Treatment Unit: An Attempt to Standardize Cold Plasma Treatment for Defined Biological Effects," Plasma Med., vol. 8, no. 2, pp. 195-201, 2018.

[21] S. Bekeschus, C. Seebauer, K. Wende, and A. Schmidt, "Physical plasma and leukocytes - immune or reactive?," Biol. Chem., vol. 400, no. 1, pp. 63-75, Dec 192018.

[22] S. Bekeschus, D. Meyer, K. Arlt, T. von Woedtke, L. Miebach, E. Freund, et al., "Argon Plasma Exposure Augments Costimulatory Ligands and Cytokine Release in Human Monocyte-Derived Dendritic Cells," Int. J. Mol. Sci., vol. 22, no. 7, p. 3790, 2021.

[23] S. Bekeschus, A. Schmidt, H. Jablonowski, L. Bethge, S. Hasse, K. Wende, et al., "Environmental Control of an Argon Plasma Effluent and Its Role in THP-1 Monocyte Function," IEEE Trans. Plasma Sci., vol. 45, no. 12, pp. 3336-3341, Dec 2017.

[24] S. Bekeschus, C. C. Winterbourn, J. Kolata, K. Masur, S. Hasse, B. M. Broker, et al., "Neutrophil extracellular trap formation is elicited in response to cold physical plasma," J. Leukoc. Biol., vol. 100, no. 4, pp. 791-799, Oct 2016. 
[25] S. Bekeschus, A. Schmidt, L. Bethge, K. Masur, T. von Woedtke, S. Hasse, et al., "Redox Stimulation of Human THP-1 Monocytes in Response to Cold Physical Plasma," Oxid. Med. Cell. Longev., vol. 2016, no. p. 5910695, 2016.

[26] E. Freund, J. Moritz, M. Stope, C. Seebauer, A. Schmidt, and S. Bekeschus, "Plasma-Derived Reactive Species Shape a Differentiation Profile in Human Monocytes," Applied SciencesBasel, vol. 9, no. 12, Jun 22019.

[27] S. Bekeschus, J. Kolata, A. Muller, A. Kramer, K.-D. Weltmann, B. Broker, et al., "Differential Viability of Eight Human Blood Mononuclear Cell Subpopulations After Plasma Treatment," Plasma Med., vol. 3, no. 1-2, pp. 1-13, 2013.

[28] S. Bekeschus, K. Rödder, A. Schmidt, M. B. Stope, T. von Woedtke, V. Miller, et al., "Cold physical plasma selects for specific T helper cell subsets with distinct cells surface markers in a caspasedependent and NF-кB-independent manner," Plasma Process. Polym., vol. 13, no. 12, pp. 1144-1150, 2016.

[29] S. Bekeschus, K. Masur, J. Kolata, K. Wende, A. Schmidt, L. Bundscherer, et al., "Human Mononuclear Cell Survival and Proliferation is Modulated by Cold Atmospheric Plasma Jet," Plasma Process. Polym., vol. 10, no. 8, pp. 706-713, Aug 2013.

[30] S. Bekeschus, T. von Woedtke, A. Kramer, K.-D. Weltmann, and K. Masur, "Cold Physical Plasma Treatment Alters Redox Balance in Human Immune Cells," Plasma Med., vol. 3, no. 4, pp. 267-278, 2013.

[31] S. Hofmann, A. F. H. van Gessel, T. Verreycken, and P. Bruggeman, "Power dissipation, gas temperatures and electron densities of cold atmospheric pressure helium and argon RF plasma jets," Plasma Sources Sci. T., vol. 20, no. 6, 2011.

[32] M. Dünnbier, M. M. Becker, S. Iseni, R. Bansemer, D. Loffhagen, S. Reuter, et al., "Stability and excitation dynamics of an argon micro-scaled atmospheric pressure plasma jet," Plasma Sources Sci. T., vol. 24, no. 6, 2015.

[33] A. V. Pipa, J. Koskulics, R. Brandenburg, and T. Hoder, "The simplest equivalent circuit of a pulsed dielectric barrier discharge and the determination of the gas gap charge transfer," Rev. Sci. Instrum., vol. 83, no. 11, p. 115112, Nov 2012.

[34] R. Matthes, A. Luhrman, S. Holtfreter, J. Kolata, D. Radke, N. O. Hubner, et al., "Antibacterial Activity of Cold Atmospheric Pressure Argon Plasma against 78 Genetically Different (mecA, luk-P, agr or Capsular Polysaccharide Type) Staphylococcus aureus Strains," Skin Pharmacol. Physiol., vol. 29, no. 2, pp. 83-91, 2016.

[35] C. Wiegand, O. Beier, K. Horn, A. Pfuch, T. Tolke, U. C. Hipler, et al., "Antimicrobial impact of cold atmospheric pressure plasma on medical critical yeasts and bacteria cultures," Skin Pharmacol. Physiol., vol. 27, no. 1, pp. 25-35, 2014.
[36]
P. Heirman, W. Van Boxem, and A. Bogaerts, "Reactivity and stability of plasma-generated oxygen and nitrogen species in buffered water solution: a computational study," Phys. Chem. Chem. Phys., vol. 21, no. 24, pp. 12881-12894, Jun 282019.

D. Marinov and N. S. J. Braithwaite, "Power coupling and electrical characterization of a radio-frequency micro atmospheric pressure plasma jet," Plasma Sources Sci. T., vol. 23, no. 6, 2014.

V. A. Godyak and R. B. Piejak, "In situ simultaneous radio frequency discharge power measurements," Journal of Vacuum Science \& Technology A: Vacuum, Surfaces, and Films, vol. 8, no. 5, pp. 3833-3837, 1990.

K. Wende, T. von Woedtke, K. D. Weltmann, and S. Bekeschus, "Chemistry and biochemistry of cold physical plasma derived reactive species in liquids," Biol. Chem., vol. 400, no. 1, pp. 19-38, Dec 192018.

W. V. Gaens, S. Iseni, A. Schmidt-Bleker, K. D. Weltmann, S. Reuter, and A. Bogaerts, "Numerical analysis of the effect of nitrogen and oxygen admixtures on the chemistry of an argon plasma jet operating at atmospheric pressure," New J Phys, vol. 17, no. 3 , p. $033003,2015$.

S. Iseni, P. J. Bruggeman, K.-D. Weltmann, and S. Reuter, "Nitrogen metastable (N2(A3 $\Sigma \mathrm{u}+)$ ) in a cold argon atmospheric pressure plasma jet: Shielding and gas composition," Appl. Phys. Lett., vol. 108, no. 18, 2016.

K. Wende, P. Williams, J. Dalluge, W. V. Gaens, H. Aboubakr, J. Bischof, et al., "Identification of the biologically active liquid chemistry induced by a nonthermal atmospheric pressure plasma

jet," Biointerphases, vol. 10, no. 2, p. 029518, Jun 62015.
A. Schmidt-Bleker, S. A. Norberg, J. Winter, E. Johnsen, S. Reuter, K. D. Weltmann, et al., "Propagation mechanisms of guided streamers in plasma jets: the influence of electronegativity of the surrounding gas," Plasma Sources Sci. T., vol. 24, no. 3, May 2015. L. Bundscherer, S. Bekeschus, H. Tresp, S. Hasse, S. Reuter, K.-D. Weltmann, et al., "Viability of Human Blood Leukocytes Compared with Their Respective Cell Lines after Plasma Treatment," Plasma

Med., vol. 3, no. 1-2, pp. 71-80, 2013.
S. Bekeschus, A. Schmidt, F. Niessner,

and K. Wende, "Basic Research in Plasma Medicine - A Throughnut Approach from Liquids to Cells," J Vis Exp, 129, p. e56331, Nov 17 2017. 